\title{
Errata: Optimal land use/land cover classification using remote sensing imagery for hydrological modeling in a Himalayan watershed
}

\author{
Sameer Saran, ${ }^{a}$ Geert Sterk, ${ }^{b}$ and Suresh Kumar ${ }^{a}$ \\ ${ }^{a}$ Indian Institute of Remote Sensing (NRSC), 4 Kalidas Road, \\ Dehradun, Uttarankhand, India \\ sameer@iirs.gov.in \\ ${ }^{b}$ Utrecht University, Department of Physical Geography, P.O. Box 80115, 3508 TC \\ Utrecht, The Netherlands \\ g.sterk@geo.uu.nl
}

This article [J. Appl. Remote Sens. 3, 033551 (2009)] was originally published online on 2 October 2009. Sameer Saran was erroneously affiliated with Utrecht University. In addition, a biography for Geert Sterk was omitted. The correct author list is shown above and the missing biography follows. These corrections were made to the article on 23 November 2009.

Dr. Geert Sterk is a university lecturer and specialist in land degradation. He teaches land degradation subjects at Utrecht University, the Netherlands, and has been conducting research on wind and water erosion processes since 1992. Most of his research focuses on the biophysical aspects of land degradation and development of models for quantification of wind and water erosion. 